Journal of Research in Interprofessional

Practice and

Education

Vol. 4.2

September 2014
Journal of Research in Interprofessional Practice and Education (JRIPE)

Vol. 4.2

(C) 2014

Corresponding author: Pamela Wener. Email: Pam.Wener@med, !umanitoba.ca.'

\section{Internalizing Client-Centredness in Occupational Therapy Students}

\author{
Jacquie Ripat, PhD, OT Reg. (MB); Pamela Wener, PhD. (C), \\ OT Reg. (MB); Kendra Dobinson, MOT, OT Reg. (Ont.); \& \\ Cynthia Yamamoto, BSc, MOT, OT Reg. (MB)
}

\begin{abstract}
Background: Pre-licensure interprofessional education prepares students for collaborative client-centred practice. However, most interprofessional educational efforts are aimed at developing the collaborative component of practice. The purpose of this article is to share the findings of a study that explored occupational therapy students' client-centred development, in order to inform other pre-licensure educators about integrating client-centredness into uni- and interprofessional education contexts.

Methods and Findings: Twenty-nine participants were recruited from each of three stages assumed to be representative of occupational therapy client-centred development in each of the two years of the educational program and during the first year of practice. Semi-structured focus groups were used to capture the participants' experiences. The core emergent theme, internalizing client-centredness, included three main processes: identifying occupational therapy as a client-centred profession, engaging in the push and pull of client-centredness, and defining self as a client-centred practitioner.

Conclusions: Educators of pre-licensure health care students should deliberately focus on client-centredness in their uni- and interprofessional education curricula; the authors offer examples of curricular opportunities focused on internalizing client-centredness. Enabling health care students to internalize client-centredness may be an important aspect of developing practitioners who are prepared to enact interprofessional collaboration for client-centred practice.
\end{abstract}

Keywords: Client-centredness; Pre-licensure education; Interprofessional education; Qualitative study

\section{Introduction}

Educators from Canada, the United Kingdom, and the United States are expected to prepare students to become collaborative client-centred practitioners ${ }^{1}$ [1-5]. Collaborative client-centred practice promotes engagement of each profession working with clients and their families [6] to enhance client- and family-centred goals and values [3]. Although there is consensus that client-centredness is important [7], there is less agreement about what that means [8]. While Rogers [9] described client-centredness as including an empathic, unconditional positive regard and genuineness, others define client-centredness as a belief that the client is the central factor of the healthcare system $[6,10]$. Over the past 30 years Canadian occupational therapists have embraced client-centredness as a core value of their profession [11-13]. In addition to notions of client-centredness articulated by others, occupational therapy scholars have included concepts of power-sharing, respecting diversity, adopting a holistic perspective of the client, and ensuring services are provided in a way that is accessible and congruent within the context of the client's living environment [14-16]. Despite 
2

Internalizing ClientCentredness

Ripat, Wener, Dobinson, \& Yamamoto

Journal of Research in Interprofessional Practice and Education

Vol. 4.2 September 2014 differences in terminology, there is widespread acceptance that being a client-centred practitioner is foundational to interprofessional collaboration in the context of delivery of health services [17].

Interprofessional education (IPE) for collaborative patient-centred practice is a key strategy to improve patient care [18] that occurs "when students from two or more professions learn with, from and about each other to improve collaboration and quality of care" [19]. The objective of pre-licensure IPE is to prepare students to work collaboratively to improve the quality of patient care through client-centred practice $[4,17]$; a small but growing body of evidence supports achievement of this objective [20].

Health and social care educators are invested in developing and implementing pre-licensure IPE opportunities guided by specific IPE learning objectives [21]. More recently, Canadian educators, researchers, and policy-makers have worked to develop a national competency framework to guide curriculum design and implementation [4,17]. The Canadian Interprofessional Health Collaborative (CIHC) interprofessional collaboration competency framework includes two core competency domains, patient/client/family/community-centred care and interprofessional communication, and four additional competency domains, role clarification, team functioning, collaborative leadership, and interprofessional conflict resolution [17]. Taken together the six competencies form a framework of interprofessional collaboration that is intended to guide interprofessional education and practice.

The CIHC competency framework makes the critical nature of client-centred practice explicit; however, reports of pre-licensure IPE primarily focus on approaches to building interprofessional collaborative relationships between health professionals. In a recent search on "interprofessional collaboration," "interprofessional education," and "patient/client/individual/family-centred" care in CINHAL, Scopus, PubMed, and PsycINFO, we found few studies that addressed how pre-licensure health professional students develop client-centredness. Existing research operationalizes the client-centred concept by focusing on the development of particular skill sets or behaviours to be used in the context of interprofessional teams. Examples of this body of work include studying the development of client-centred communication skills among social work and physical therapy students [22] and assessing occupational and physical therapy students' learning of home assessment skills [23]. Other authors have looked at client involvement in the education of health professionals as a means of enhancing client-centredness; Vingilis et al. [24] held a series of IPE workshops that included mental health consumers, where the vast majority of participating students (91\%) agreed that the workshop highlighted the importance of client-centred communication. Incorporating client mentors into team-based pre-licensure learning activities has been used as a means of promoting empathy development [25], and client storytelling in a problem-based learning capacity has been implemented in combined groups of students and practitioners [26]. Moreover, it has been demonstrated that clients are interested in educating and mentoring students, thereby making a meaningful contribution to improving the healthcare system [27].

The centrality of the client has been emphasized by patient educators, who highlight the need to place the client at the centre of the interprofessional team, to com- 
3

Internalizing ClientCentredness

Ripat, Wener, Dobinson, \& Yamamoto

Journal of Research in Interprofessional Practice and Education

Vol. 4.2

September 2014 municate in a respectful manner, to work to understand the impact of the condition on the person in a holistic manner, and, above all, to ensure that clients are "people first" [27]. In order to come together in interprofessional teams, Khalili, Orchard, Laschinger, and Farah [28] suggest that students of different health professions need to develop uni- and interprofessional identities, that is, dual identities. While a uniprofessional identity highlights differences, emphasizing shared values and attitudes such as client-centredness may make an important contribution to the development of the dual identity. Boers, Poth, and Medves explored the meaning of interprofessional care (IPC) with students from four health disciplines. The student study participants were found to have shared and profession-specific unique ideas about IPC, with OT students the only group to include client-centredness in their description/definition of IPC [29]. Thus, the purpose of this study was to explore how student occupational therapists develop client-centredness during their prelicensure education. Given occupational therapy's commitment to client-centredness, initially exploring the experiences of client-centred development from a uni-professional perspective is warranted. Findings from this study will inform curriculum developers from other pre-licensure educational programs who will be able to draw on the findings and apply them within their uniprofessional or interprofessional education context.

\section{Methods}

To gain an understanding of this development we used a grounded theory approach as described by Charmaz [30]. We assumed that a process of client-centred development would emerge as participants shared their perceptions at various stages of their pre-licensure development and into their first year post-licensure. We further assumed that participants' engagement with academic assignments and fieldwork experiences would shape their perspectives on client-centredness and that participants would reflect on their current understanding of client-centredness at each data collection point.

Data were originally collected as part of a parent study [31] where six focus groups were used to explore client-centred development of student occupational therapists. Researchers sought to discern the students' perspectives about client-centredness, including: pre-entry knowledge, curriculum experiences that shaped their perspectives, and how they thought it applied to practice. The study was approved by a university REB.

\section{Procedure}

Participants were voluntarily recruited in three cohorts from a two-year entry-level Master of Occupational Therapy program: students who completed six months of the first year of the program (MOT1) $(N=3$ and $N=5)$, six months into the second year of the program (MOT2) $(N=6$ and $N=6)$, and graduates who were within one year of post-licensure practice $(N=6$ and $N=3)$ [30]. Two focus groups were facilitated for each cohort. Questions were selected to evoke participants' perspectives on their development of the client-centred knowledge, skills, and attitudes required of 
4

Internalizing ClientCentredness

Ripat, Wener, Dobinson, \& Yamamoto

Journal of Research in Interprofessional Practice and Education

Vol. 4.2

September 2014 them to practice as occupational therapists. The focus groups were audio-taped, transcribed, and anonymized. Focus groups were utilized to collect the group perspective and enhance data quality as participants considered input from their peers as well as their own thoughts and reflections [32]. Focus group participants were from the same MOT cohort and shared experiences that enabled a deep discussion.

\section{Data analysis}

We used an inductive, thematic approach to data analysis. The first three authors individually conducted open coding on each transcript, and then met to develop agreement on coding and the list of codes prior to proceeding to code the next transcript. The transcripts were coded in order of student progression (i.e., MOT1, then MOT2, then new graduates). Once coding was completed, the researchers worked collaboratively to develop, reduce, and refine categories from the coded transcripts. Categories were grouped into six overarching themes; subsequently, relationships between themes were explored. A framework was developed to support the findings based on analysis of the data and further review of the literature [30]. Trustworthiness was addressed through triangulation of investigators and sources, member-checking to ensure participant ideas were not misconstrued, and an audit trail recording development of the data analysis. In this report, further analysis of the theme internalizing client-centredness, from the original study, was completed by the first two authors (PW \& JR). Internalizing client-centredness referred to the "ways in which students and graduates felt they 'became' client-centred in their thinking, attitudes and behaviours, and began to identify themselves as client-centred practitioners" [30]. The authors sought to explicate this theme in order to better understand the processes involved and implications for interprofessional education.

\section{Results}

Three main processes occurred for participants while internalizing client-centredness: identifying occupational therapy as a client-centred profession, engaging in the push and pull of client-centredness, and defining self as a client-centred practitioner. Participants described engaging in cycles of action and reflection that served to deepen their understanding of each process. To ensure clarity of the direct quotes from participants, the authors removed filler words and replaced them with ellipses.

\section{Identifying occupational therapy as a client-centred profession}

Participants described how they quickly learned of the importance that the occupational therapy profession placed on client-centredness. Most had heard the term in preparation for application to their pre-licensure program, and recognized it was a concept that held value to those in the profession. However, the rhetoric around client-centredness was not well understood at the early stages of their program:

I read a lot about what client-centred is, but I didn't really know how to do it. (MOT1) 
Internalizing ClientCentredness

Ripat, Wener, Dobinson, \& Yamamoto
Journal of Research in Interprofessional Practice and Education

Vol. 4.2

September 2014

\section{Journal of Research in Interprofessional Practice and Education}

For some, congruency between the profession's emphasis on client-centredness and their pre-existing values and beliefs attracted them to enter the profession. However, while they may have been thinking in a client-centred way prior to entering their program, they hadn't labelled it as such:

I don't think I'd ... heard the term before getting into the program ... but ... in looking into ... what OT was ... I was really attracted to ... the OT philosophy ..., being really holistic and you look at the whole person and you consider their values. (MOT2)

Participants were able to link their previous experience and knowledge to clientcentredness. Furthermore, the participants were able to recognize how labelling past experiences as client-centred was important for connecting with an abstract concept.

I used to coach water polo, and being client-centred with my players [was important] because if we were doing activities they didn't want to do then they wouldn't want to practice and they didn't want to play. But if you ... made games out of swimming laps and stuff, they were more motivated to [become] involved. (MOT2)

While the concepts of client-centredness were introduced to participants early in their pre-licensure education program, they were re-emphasized throughout. The students recognized that the repetitiveness was indicative of the central role that client-centredness occupies in the occupational therapy profession.

I kind of feel like, "okay, I get it, let's move on," but I guess because it is such a central aspect of our profession, I can understand why it's incorporated so much, and ... I want us to always be thinking about that. (MOT2)

\section{Engaging in the push and pull of client-centredness}

\section{Respecting client diversity}

Participants began to appreciate how client views and choices could be different than their own, and how understanding and respecting diversity in individuals was an important element of client-centredness and the need to look beyond their own experiences.

If I go to ... do a home assessment and ... they hoard magazines and

I see that this is an unsafe environment ... I have to learn that this is their lifestyle and that is how they want to live, and so for me, just accepting that ... and not rationalizing it .... (MOT1)

Sometimes they struggled with the differences in values and choices but recognized the need to respect those differences even when they differed from their own.

We had to be client-centred in that ... we can't force her to accept any of our services, so we had to ... send her home, knowing that ... she would be right back in, ... so, it's a struggle .... (MOT2) 
Internalizing ClientCentredness

Ripat, Wener, Dobinson, \& Yamamoto
Journal of Research in Interprofessional Practice and Education

Vol. 4.2

September 2014

\section{Journal of Research in Interprofessional Practice and Education}

\section{Seeking to understand}

To use their communication skills to seek deeper understanding, rather than assuming, was viewed as essential to the participants' ability to be client-centred in interactions.

That never would have occurred to me to ask someone what kind of utensils they use, ... I would just assume that everyone used a fork and a knife, so I think it ... really made me more aware of ... different cultures and ... how much I ... assume ..., and [this experience of a client who used an ulu] reinforced that you actually need to ask questions. (MOT2)

Student participants began to identify how development of empathy and understanding was a key aspect of client-centredness.

Just thinking how or what it is like to be that client and what would be important to us ... I think having those [disability] simulations really helped ... in showing us what we have to look for to help our clients get what they need. (MOT1)

\section{Recognizing clients as individuals}

Participants began to be able to "step outside" of themselves to see and treat people as individuals, and to see how this was consistent with acting in a client-centred manner. One participant shared how this included learning to withhold judgment:

In my last fieldwork, the client-centred lesson I learned was just meeting the client where they're at, [be]cause sometimes it was so easy to get frustrated, ... you'd arrange to meet a client at a certain time and they wouldn't be there, they wouldn't show up ..., but you just have to understand [that] the way that their life is right now they're just not used to being somewhere on time. (MOT2)

Furthermore, the participants observed that each person had unique interests and abilities. They observed that individualizing their interactions with their clients was meaningful and motivating to the client. This realization emphasized for them how respecting and responding to individual diversity was congruent with ideas of clientcentredness. Throughout their educational program, student participants were exposed to experiences and opportunities that either confirmed and reinforced or challenged their developing ideas of client-centredness.

[On one] of my placements, we got to work with a population with dementia. How do you truly be client-centred? ... I saw people talking almost through them or around them. I realized how important being client-centred was because I couldn't fathom ... not looking directly at the person and still talking to them ... despite the fact that they might not be cognitively there. (MOT2)

\section{Reinforcing the importance of client-centredness}

Sometimes reinforcement of the approach was through sharing of professional rea- 
7

Internalizing ClientCentredness

Ripat, Wener, Dobinson, \& Yamamoto
Journal of Research in Interprofessional Practice and Education

Vol. 4.2

September 2014 soning about client-centredness by faculty members and fieldwork educators, and the opportunity for students to learn implicitly through the challenges faced by others:

I had one educator who was struggling with it [client-centredness] because there was a client with an incomplete spinal cord injury who could sort of walk, and he refused to take a wheelchair when he left the hospital, and so she [said] ... "I don't know what to do, you know, cause he really needs this, but he won't have it, and so I want to respect what he [wants]" ... really made an impact on me. (MOT2)

In their academic program, assignments intentionally focused on client-centredness, opportunities to explore client-centredness, and reflection on client-centredness reinforced the concept's importance. As students gained more knowledge and client-based experiences, they recognized the restrictive nature of assignments that used a case-based approach to teach occupational therapy assessment and treatment processes. Students recognized that paper cases did not allow for authentic engagement with a client; however, this restriction strengthened the importance they placed on client-centredness in practice.

When it is just written on paper, and you start reading and you're supposed to determine ... what would you do with this person, it really makes me think, ... "I need to know this person, I need to know their values," so it reinforces that client-centredness. So I think ... having things that aren't as client-centred for students reinforces that [it] is so important, to really know the person. (MOT2)

\section{Defining self as a client-centred practitioner}

Ultimately, client-centredness became part of the participants' professional identity, and they were able to recognize their change in perspective over the time in the program by reflecting on the process of internalizing:

I think [client-centredness has] been formed into something that's just part of us as ... OT students, ... it's hard to figure out ... what I thought it was before, and ... what I think it is [now]. It's evolved quite a bit I think. (MOT2)

At this later stage of their professional education and into their first year of practice, the participants were able to view client-centredness as a flexible approach, rather than something rigid and prescribed. While they continued to experience challenges in applying a client-centred approach in practice, they were able to demonstrate actions that aligned with their internalization of client-centredness:

My experience with applying [a] client-centred approach [has] been quite a struggle. ... An example of this ... that has really come up in our facility is the least restraint and fall risk management and being client-centred with that. And not just educating the staff on the different interventions for fall risk management but ... I have a couple 
8

Internalizing ClientCentredness

Ripat, Wener, Dobinson, \& Yamamoto
Journal of Research in Interprofessional Practice and Education

Vol. 4.2

September 2014 residents ... at risk of falling [who are] able to make their own decisions, and so educating them on the benefits of hip protectors and wheelchair alarms and that sort of thing. (New Grad)

As new occupational therapists, these participants internalized the value of adopting a holistic and individualized view of the client that they believed distinguished occupational therapy from other professions. Recent graduates of the program saw client-centredness as a defining feature of the profession.

I guess it's hard to put a finger on it other than ... it's the attitude, the outlook that I have ... is different [from] some of the other people that are on the team. (New Grad)

Overall, participants felt prepared to enter practice as a client-centred practitioner: There's so many areas in OT, and there's so many things to know that you specifically can't know everything while going out [to practice], but you at least know how to be client-centred. (MOT2)

\section{Discussion}

In the current study, participants developed a sense of themselves as client-centred practitioners, who began the process of internalizing the attitudes, values, interests, knowledge, and skills required to participate as a member of the profession [33,34]. Focus group participants were drawn from different cohorts rather than studied longitudinally. Despite this sampling approach, we noted a developmental process to internalizing client-centredness. MOT1 and MOT2 participants (reflecting on their earlier educational experiences) tended to focus on conveyance and acceptance of client-centredness as a professional value. While reflecting on their experiences across the entire academic program, participants discussed the challenges they faced in trying to implement client-centred approaches and integrate client-centred values. Participants at later stages of their professional development (MOT2 and New Grad participants) expressed how they had become client-centred, using language to express their internalization and where client-centredness became an innate part of their professional identity.

Overall, our findings support this statement: "Absent these attitudes, one can act in a patient-centred way but will not really be patient-centred" [35]. In this study, the pre-licensure students underscored the influential role of the curriculum, faculty, and practitioner educators in developing an internalized attitude of client-centredness. Participants described how observing therapists incorporate clients into the goal setting, treatment planning, and implementation impacted their developing client-centredness. Developing an attitude that places value on meaningful involvement of individuals may be an important element of client-centred collaborative practice healthcare [36].

Pre-licensure academic and fieldwork education, as well as early workplaces, are key environments where students and new graduates receive socialization influences that enable them to identify and internalize what it means to be a part of their par- 
9

Internalizing ClientCentredness

Ripat, Wener, Dobinson, \& Yamamoto
Journal of Research in Interprofessional Practice and Education

Vol. 4.2

September 2014 ticular health profession [33]. A process of "consistent socialization" [34] occurred, with a consistent emphasis on client-centredness in multiple environments throughout the academic and fieldwork pre-licensure education. This process enabled students to perceive and internalize client-centredness as a defining feature of occupational therapy. However, near the end of their pre-licensure program, participants began to express their "individual agency" [33] by experimenting with ideas of client-centredness and its dynamic nature, despite this socialization process. Participants began to recognize that client-centredness could be expressed in different ways, but that the internalization of the attitude was central.

\section{Table 1}

\section{Uni- and interprofessional curricular opportunities focused on internalizing client-centredness}

\begin{tabular}{|c|c|}
\hline Internalizing process and timing & Curricular opportunities \\
\hline $\begin{array}{l}\text { Identifying and emphasizing } \\
\text { client-centredness within ones' } \\
\text { professions } \\
\text { Early in pre-licensure training }\end{array}$ & $\begin{array}{l}\text { - Provide uni- and interprofessional learning opportunities that encourage and } \\
\text { support students in defining and exploring client-centredness. } \\
\text { - Focus on exploring ways in which client-centredness fits within one's profes- } \\
\text { sional context, discourse, and theories. } \\
\text { - Convey the importance of client-centredness as a foundational IPC compe- } \\
\text { tency by providing IPE opportunities for students where educators point out } \\
\text { client-centred experiences and situations. }\end{array}$ \\
\hline $\begin{array}{l}\text { Engaging with the push and pull } \\
\text { of client-centredness } \\
\text { Midway through to end of pre- } \\
\text { licensure program }\end{array}$ & $\begin{array}{l}\text { - Provide values clarification exercises to support students in learning about } \\
\text { and responding to diversity. } \\
\text { - Observe and dialogue with role models as students begin to experience the } \\
\text { rewards and difficulties associated with being a client-centred practitioner. } \\
\text { - Provide fieldwork in varied environments with frequent opportunities for } \\
\text { integration and debriefing about client-centredness. }\end{array}$ \\
\hline $\begin{array}{l}\text { Defining self as a client-centred } \\
\text { practitioner } \\
\text { Towards end of pre-licensure pro- } \\
\text { gram and into post-licensure } \\
\text { practice }\end{array}$ & $\begin{array}{l}\text { - Encourage students to explore and apply the spirit of client-centredness in a } \\
\text { dynamic and flexible, rather than static manner. } \\
\text { - Provide clinical reasoning opportunities that encourage students to consider } \\
\text { client-centredness in complex health and social environments. } \\
\text { - Provide learning platforms such as professional interest groups and continu- } \\
\text { ing education to consolidate theory and practice of client-centredness } \\
\text { towards the end of the education program and into the first years of practice. } \\
\text { - Promote intentional reflection on students' own client-centred develop- } \\
\text { ment/changing perspective. }\end{array}$ \\
\hline
\end{tabular}

Focusing on similarities tends to break down interprofessional boundaries and makes a positive contribution to the interprofessional socialization process [28]. Furthermore, interprofessional role learning may be enriched when interprofessional learners focus on the development of the six interprofessional collaboration competencies [17]. This study suggests that occupational therapy students recognize the central and foundational place of client-centredness within the occupational therapy profession. However, there is little focus on client-centredness within IPE. Providing pre-licensure IPE opportunities that include a focus on client-centredness 


\section{JRIPE}

10

Internalizing Client-

Centredness

Ripat, Wener, Dobinson, \& Yamamoto
Journal of Research in Interprofessional Practice and Education

Vol. 4.2

September 2014

\section{Journal of Research in Interprofessional Practice and Education}

may set the stage for students to discover their similarities and make an important contribution to the students' developing interprofessional identity.

Thus, in terms of pre-licensure curriculum planning, there are a number of recommendations that educators may consider in their efforts to enhance development of the interprofessional competency of client-centredness. Table 1 outlines specific curricular opportunities aligned with the developmental processes of internalizing client-centredness.

\section{Limitations}

Limitations of this study include that participants were recruited from different cohorts (rather than studied longitudinally), and from only one university program. Several future research opportunities exist. A longitudinal study following one cohort over time would elucidate whether the processes identified occur in a particular developmental sequence. Other research could include exploring the client perspective, the processes and experiences of other professional health care programs and their students, and conducting interprofessional pre-licensure student focus groups.

\section{Conclusion}

Examination of the theme internalizing client-centredness revealed three processes for occupational therapy students and first-year practitioners: identifying occupational therapy as a client-centred profession, engaging in the push and pull of client-centredness, and defining self as a client-centred practitioner. While client-centredness has been identified as a foundational interprofessional competency, the focus in IPE to date has mostly been on the collaborative relationship between healthcare providers, exclusive of the client. Planners of pre-licensure IPE opportunities may want to consider including more intentional focus on client-centredness, and the authors have provided curricular opportunities (Table 1) that align with the three processes of internalizing client-centredness noted. Centring the client in learning about interprofessional collaborative practice provides a meaningful focal point for pre-licensure students, ultimately contributing to the aim of improving the quality of care provided to our clients.

\section{Acknowledgements}

The first two authors of this manuscript (JR, PW) provided equal contribution to the conceptualization and writing of this manuscript and consider themselves to have shared the role of first author. Thank you to the participants of this study for sharing their insights.

\section{Note}

1. In this article we have purposely chosen to use the term "client" to represent the person who collaborates with the practitioner, with the shared goal of improving the client's health, as in CIHC competency 3 . 
11

Internalizing ClientCentredness

Ripat, Wener, Dobinson, \& Yamamoto

Journal of Research in Interprofessional Practice and Education

Vol. 4.2

September 2014

\section{References}

1. Accreditation of Interprofessional Health Education. (2011). AIPHE interprofessional health education accreditation standards guide [phase 2]. URL: http://www.cihc.ca/files/resources /public/English/AIPHE\%20Interprofessional\%20Health\%20Education\%20Accreditation\%20St andards\%20Guide_EN.pdf [June 17, 2014].

2. Centre for the Advancement of Interprofessional Education. (2007). Executive summary of creating an interprofessional workforce: An education and_training framework for_health and social sake in England__UR_: http:/_webarchive nationalarchives.gov.uk/20130107105354/http:/Lwww.dh.govi Luk_en/Publicationsandstatistics/Publications/PublicationsPolicy_AndGuidance/DH_078593! [June 17, 2014].

3. Health_Canada._(2003)__Romanow _eport_proposes_sweeping changes to medicare. URL:

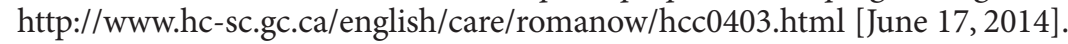

4. Interprofessional Education Collaborative (IPEC). (2011). Core competencies for interprofessional collaborative_practice: Report of an expert_panel_ National_Network of_Libraries of Medicine. URL:'http://nnlm.gov/bhic/2011/05/26/core-competencies-interprofessional/i'[June 17, 2014].

5. World Health Organization. (WHO). (2010). Eramework for_action on interprofessional_edusation_\& ,

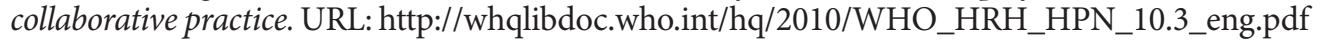
[June 17, 2014].

6. Reeves, S., Goldman, J., Burton, A., \& Sawatzky-Girling, B. (2010). Synthesis of systematic review evidence of interprofessional education. Journal of Allied Health, 39(3), 198-203.

7. Little, P., Everitt, H., Williamson, I., Warner, G., Moore, M., Gould, C., Ferrier, K., \& Payne, S. (2001). Preferences of patients for patient centred approach to consultation in primary care: Observational study. British Medical Journal, 322(7284), 468-472.

8. Dwamena, F., Holmes-Rovner, M., Gaulden, C.M., Jorgenson, S., Sadigh, G., Sikorskii, A., Lewin, S., Smith, R.C., Coffey, J., \& Olomu, A. (2012). Interventions for providers to promote a patient-centred approach in clinical consultations. Cochrane Database of Systematic Reviews, Issue 12. [Art. No.: CD003267].

9. Rogers, C.R. (1951). Client-centered therapy: Its current practice, implications, and theory. Cambridge, MA: The Riverside Press.

10. Ontario Medical Association (OMA). (2010). Policy paper: Patient-centred care. Ontario Medical Review, 77, 34-49.

11. Department of National Health and Welfare (DNHW) \& Canadian Association of Occupational Therapists (CAOT). (1983). Guidelines for the client-centred practice of occupational therapy. [Cat. No. H39-33/1983E]. Ottawa, ON: Author.

12. Canadian Association of Occupational Therapists (CAOT). (1997). Enabling occupation: An occupational therapy perspective. Ottawa, ON: CAOT Publications ACE.

13. Townsend, E., \& Polatajko, H. (2007). Enabling occupation II: Advancing an occupational therapy vision for health, well-being \& justice through occupation. Ottawa, ON: CAOT Publications ACE.

14. Law, M., Baptiste, S., \& Mills, J. (1995). Client-centred practice: What does it mean and does it make a difference? Canadian Journal of Occupational Therapy, 62(5), 250-257.

15. Sumsion, T. (2000). A revised occupational therapy definition of client-centred practice. British Journal of Occupational Therapy, 63(7), 304-309.

16. Sumsion, T., \& Law, M. (2006). A review of evidence on the conceptual elements informing clientcentred practice. Canadian Journal of Occupational Therapy, 73(3), 153-162.

17. Canadian Interprofessional_Health_Collaborative._2010). A national_interprofessional competency

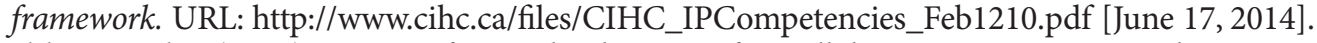

18. Health Canada. (2006)_. Interprofessional_education _for collaborative _patient-centred_practice:

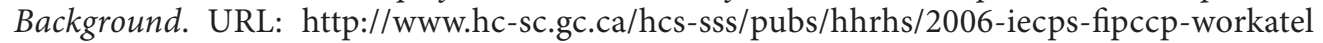
indindex-eng.php! .[June 17,2014].

19. Centre for the _Adyancement_ of_Interprofessional Education. (2002). Defining IPE. URL:

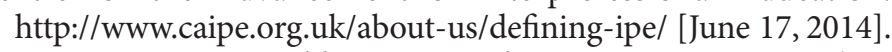

20. Reeves, S., Perrier, L., Goldman, J., Freeth, D., \& Zwarenstein, M. (2013). Interprofessional education: Effects on professional practice and healthcare outcomes [update]. Cochrane Database of Systematic Reviews, Issue 3. [Art. No.: CD002213].

21. Wener, P. (2013). Developing educational opportunities to teach interprofessional team communication skills. Journal of Interprofessional Care, 27(S1), 48.

22. Cavanaugh, J.T., \& Konrad, S.C. (2012). Fostering the development of effective person-centred healthcare communications skills: An interprofessional shared learning model. Work, 41(3), 293-301. 
JRIPE

12

Internalizing Client-

Centredness

Ripat, Wener, Dobinson, \& Yamamoto

\section{Journal of Research in Interprofessional Practice and Education}

23. Sabus, C., Sabata, D., \& Antonacci, D. (2011). Use of a virtual environment to facilitate instruction of an interprofessional home assessment. Journal of Allied Health, 40(4), 199-205.

24. Vingilis, E., Forchuk, C., Orchard, C., Shaw, L., King, G., McWilliam, C., Khalili, H., Edwards, B., \& Osaka, W. (2011). Development, implementation, and formative evaluation of pre-licensure workshops using participatory action research to facilitate interprofessional, client-centred mental healthcare. Journal of Research in Interprofessional Practice and Education, 2(1).

25. Doucet, S., Andrews, C., Godden-Webster, A. L., Lauckner, H., \& Nasser, S. (2012). The Dalhousie Health Mentors Program: Introducing students to collaborative patient/client-centred practice. Journal of Interprofessional Care, 26(4), 336-338.

26. Furness, P.J., Armitage, H., \& Pitt, R. (2011). An evaluation of practice-based interprofessional education initiatives involving service users. Journal of Interprofessional Care, 25(1), 46-52.

27. Doucet, S., Lauckner, H., \& Wells, S. (2013). Patients' messages as educators in an interprofessional health education program. Journal of Research in Interprofessional Practice and Education, 3(1).

28. Khalili, H., Orchard, C., Laschinger, H.K., \& Farah, R. (2013). An interprofessional socialization framework for developing an interprofessional identity among health professions students. Journal of Interprofessional Care, 27(6), 448-453.

29. Broers, T., Poth, C., \& Medves, J. (2009). What's in a word? Understanding “interprofessional collaboration" from the students' perspective. Journal of Research in Interprofessional Practice and Education, 1(1).

30. Charmaz, K. (2006). Constructing grounded theory. Los Angeles: SAGE Publications.

31. Ripat, J., Wener, P., \& Dobinson, K. (2013). The development of client-centredness in student occupational therapists. British Journal of Occupational Therapy, 76(5), 217-224.

32. Patton, M.Q. (2002). Qualitative research and evaluation methods, 3rd edition. Thousand Oaks, CA: Sage Publications.

33. Clouder, L. (2003). Becoming professional: Exploring the complexities of professional socialization in health and social care. Learning in Health and Social Care, 2(4), 213-222.

34. Sabari, J.S. (1985). Professional socialization: Implications for occupational therapy education. American Journal of Occupational Therapy 39(2), 96-102.

35. Duggan, P.S., Geller, G., Cooper, L.A., \& Beach, M.C. (2006). The moral nature of patient-centeredness: Is it "just the right thing to do"? Patient Education and Counseling, 62, 271-276.

36. Orchard, C.A., Curran, V., \& Kabene, S. (2005). Creating a culture for interdisciplinary collaborative professional practice. Medical Education Online 10(11).
Journal of Research in Interprofessional Practice and Education

Vol. 4.2

September 2014 